\title{
Recent Research on Students' Identities: Advancing Theory and Practice to Disrupt Inequities
}

\author{
Julia Gouvea* \\ Tufts University, Medford, MA 02155
}

\begin{abstract}
Students' identities shape and are shaped by learning experiences inside and outside classrooms. Three recent papers present theoretical frameworks for understanding the complex dynamics of identity development with implications for equity in science and mathematics education.
\end{abstract}

\section{INTRODUCTION}

A high ideal of science, technology, engineering, and mathematics (STEM) education is that students come to identify as part of disciplinary communities-that they develop science or mathematics identities. Ultimately, these students may transform the disciplines themselves, expanding who is seen as a scientist or mathematician and what that work looks like. For these reasons, scholarship on identity development has become integral in conversations about equity in the STEM disciplines. Three recent papers represent a current theoretical coherence in identity work, with implications for instructors and curriculum designers.

I begin with a paper by Gresalfi and Hand, because it presents an orienting framework for conceptualizing identity development. The ideas in this framework are echoed in the other two papers, giving coherence to the set. The second paper, by Visintainer, addresses identity development in high school, specifically focusing on intersections of science and race. Finally, Buenrostro and Radinsky trace identity development over years, presenting evidence of how different learning contexts did (or did not) leave traces in a student's identity.

\section{DESIGNING CLASSROOM SPACES TO SUPPORT IDENTITY DEVELOPMENT} Gresalfi, M., \& Hand, V. M. (2019). Coordinating situated identities in mathematics classrooms with sociohistorical narratives: a consideration for design. ZDM-Mathematics Education, 51(3), 493-504. https://doi.org/10.1007/ s11858-019-01034-y

Gresalfi and Hand present an organizing theoretical framework that can inform the design of classroom spaces (see Figure 1, p. 494). Their purpose is to help designers create experiences that offer students positive resources for identity building and also disrupt harmful narratives and structures of oppression. Central to their model is the basic idea that students construct identities from available "resources." Resources describe the source materials (positive or negative) from which identities are constructed. Gresalfi and Hand model resources at three interacting levels.

At the macro level, broad social narratives, including those about race, gender, and class, function to populate students' identities, positively reinforcing their sense of themselves as having potential or negatively threatening their identity development. Narrative resources also show up in meso-level frames-the "available scenes and storylines that organize our understanding of and predictions about what is happening in a given situation" (p. 496). The authors illustrate how frames function with an
CBE Life Sci Educ June 1, 2020 19:fe3 DOI:10.1187/cbe.20-03-0051

This feature is designed to point CBE-Life Sciences Education readers to current or noteworthy articles for life science educators and education researchers. We invite readers to suggest current themes or articles of interest in life science education as well as influential papers published in the more distant past or in the broader field of education research to be featured in Current Insights. Please send any suggestions to Julia.Gouvea@tufts.edu.

*Address correspondence to: Julia Gouvea (Julia Gouvea(atufts.edu).

(c) 2020 J. Gouvea. CBE-Life Sciences Education (c) 2020 The American Society for Cell Biology. This article is distributed by The American Society for Cell Biology under license from the author(s). It is available to the public under an Attribution-Noncommercial-Share Alike 3.0 Unported Creative Commons License (http:// creativecommons.org/licenses/by-nc-sa/3.0)

"ASCB $®$ " and "The American Society for Cell Biology $\circledast$ " are registered trademarks of The American Society for Cell Biology. 
example of a student named Brianna whose attempts to lead her group become interpreted in terms of an available frame about "female bossiness" that her peers employ. At the most micro level, specific norms and expectations for how to behave in particular spaces function to constrain behavior and talk, with consequences for identities.

Gresalfi and Hand emphasize two primary mechanisms that function within and across the three levels. Recognition is the process through which students see themselves and others as fitting with available narratives and frames. For example, how Brianna's peers recognized her as a bossy kind of woman in their math class. Positioning describes the process by which recognition is played out in interactions. Brianna is positioned by her peers as "bossy," allowing them to dismiss her contributions. Eventually, Brianna herself begins to take up this positioning, interpreting herself as "doing too much."

Both mechanisms are assumed to play out primarily through discourse, as students make sense of one another and themselves through classroom talk. Thus, Gresalfi and Hand focus on discourse at multiple levels as entry points for intervention through design. They then use their model to analyze two interventions that design for identity development at different levels.

One approach, exemplified by Gutstein (2016), aims to directly take on broader narratives of what "success" looks like in mathematics by teaching students to use mathematics as a tool for interrogating sociopolitical problems such as poverty, elections, or gentrification. Gresalfi and Hand position this work as intervening and potentially transforming the narrative resources available to students. They also use the model to identify a gap in understanding the role of micro-level norms and practices in this approach. How might students respond to and position one another in these contexts?

A second approach, exemplified by Boaler (2008), is designed explicitly around classroom norms and practices. Gresalfi and Hand use their model to highlight how Boaler designed classroom interactions to "disrupt academic and status differences" by establishing classroom norms that guided mathematical practice. They also point to a lack of knowledge around how students in these classrooms used higher-level resources (frames and narratives) to recognize and position one another.

While Gresalfi and Hand acknowledge the success of both approaches, they argue that designs that intervene at multiple levels-shifting both how students interact locally and how they make meaning of broader story lines_can be a more powerful means of transforming systems of identity development.

\section{HOW HIGH SCHOOL STUDENTS NAVIGATE RACE AND IDENTITY IN SCIENCE}

Visintainer, T. (2020). "I think at first glance people would not expect me to be interested in science": Exploring the racialized science experiences of high school students of color. Journal of Research in Science Teaching, 57(3), 393422. https://doi.org/10.1002/tea.21597

Visintainer uses identity as a means of understanding underrepresentation of students of color in science. Her focus is high school youth of color who are at a critical moment for "making decisions about who they can become in the future." Using an ecological perspective similar to Gresalfi and Hand, Visintainer models identity as constructed through interactions at the macro (e.g., society), meso (e.g., schools), and micro levels (e.g., individuals in moments).

To study how identity, race, and science intersect for high school students, Visintainer conducted semistructured interviews in which she asked 18 students about 1) characteristics associated with scientists and science, 2) understandings of racial disparities in science, and 3) their own experiences and interests in science.

Visintainer used an ecological levels perspective to analyze the interviews, attending to how students used ideas from their lives, institutional contexts, and society to narrate their identities. For example, Visintainer categorized students' sense making around underrepresentation according to where students located the problem: at the level of individual attributes (e.g., innate ability or effort), meso-level institutions (e.g., understandings of success in school), or macro-level narratives (e.g., racial discrimination).

Visintainer explored variation among students by using a pre-interview survey to sort students into self-identified categories of low, medium, and high "science ability," and then compared interviews of high $(n=5)$ and low $(n=7)$ science ability groups. Patterns across all 18 students are presented first, followed by a comparison of patterns from low and high science ability groups. Here, I will highlight three salient themes from the findings.

First, in line with prior research, students associated scientists with knowledge, power, and whiteness. Success in science was often described in terms of knowledge acquisition as measured through testing. Visintainer argues that this result shows how racialized narratives, identified decades ago, around who does science and what it means to succeed still play a dominant role in influencing students' identities. Further, these narratives are stabilized by interactions across levels (macro, meso, and micro). For example, macro-level racialized narratives about success in science are reinforced by meso-level classroom structures that define success in terms of test scores and knowing vocabulary.

Second, students' understandings of racial underrepresentation were heterogeneous - though deficit-oriented views were common (e.g., "I am some of the only people [from my population] that actually want to learn."). Visintainer emphasizes how deficit narratives create a double bind for students. If science is a domain of whiteness, then students need to overcome their own race, claiming to be "unlike the others" to become scientists.

Third, students self-identifying as high or low ability described different ways of navigating their relationships to science. Students reporting a high sense of ability emphasized that successful academic performances (i.e., high test scores) helped them persevere. Students reporting low sense of ability similarly located success in effort and persistence but described lacking those abilities (e.g., "I process slow") or pointed to systemic barriers that made effort "pointless." Both groups tended to express narratives that featured individuals "overcoming" as necessary for success.

Overall, Visintainer calls attention to persistent issues that undermine efforts to address inequities in science. In particular, the prevalence of individual-based "meritocratic" narratives provides limited pathways for identity construction among students of color. Visintainer concludes that change will require disrupting the dominant racialized narratives while diversifying 
the experiences of science learning that youth can use to author their narratives.

\section{HOW LEARNING EXPERIENCES SHAPE IDENTITY DEVELOPMENT OVER TIME}

Buenrostro, P. M., \& Radinsky, J. (2019). Looking at my (real) world through mathematics: Memories and imaginaries of math and science learning. Cognition and Instruction, 37(3), 390-407.

Buenrostro and Radinsky explore identity development on the timescale of years by presenting evidence of mathematics and science identity construction in a young Mexican man named Calvin. The authors position Calvin's case as informative, because Calvin has woven together identity resources from three different contexts of his life: high school, college, and independent learning.

The authors analyze an interview with Calvin, a participant from a larger study, 4 years after his graduation from Freedom High School (FHS). Calvin was a member of one of the first cohorts at FHS, a study site chosen by Buenrostro because of its efforts to infuse a social justice curriculum into a school that served a predominantly Latinx working-class community.

In the interview, Calvin tells a story of his relationship with mathematics learning in a social justice-oriented mathematics class (M4SJ), a reformed mathematics class (without a social justice emphasis), traditional college classes, and his own independent pursuits.

Buenrostro and Radinsky use the theoretical construct of appropriation to analyze the interview narrative. Appropriation occurs when a subject uses conceptual tools (similar to what Gresalfi and Hand call "resources") to "narrate one's own disciplinary life experiences and identity" (p. 393). Like resources, conceptual tools are not inherently positive, but rather refer to the raw materials from which identity can be constructed.

A central question motivating the authors' analysis is to look for evidence of what tools get appropriated from different learning contexts and how appropriated tools influence identity development and agency. Buenrostro and Radinsky employ methods of discourse analysis to identify evidence of appropriation in the interview transcript. They take as evidence of appropriation the consistent and intentional use of idiosyncratic phrasing to coordinate one's understanding of disciplinary and social life (p. 392).

One of the most well-developed examples of appropriation is Calvin's descriptions of "looking at the world through mathematics," a conceptual tool from his Mathematics for Social Justice class. While Calvin relayed no particular interest in "the whole social justice thing," there is evidence that he appropriated a more general conceptual tool from this course.
Specifically, Calvin frequently uses the idea of "looking at the world through mathematics" to describe his interest in using math to pursue his passion for physics and astronomy. Four years after graduation, the idea of applying math to real-life problems is part of Calvin's identity.

In contrast, there is little evidence that Calvin appropriated any conceptual tools from his traditional college math courses. Instead, Calvin refers to the lack of "imagining," "connection," and "application" in college math.

In their discussion, Buenrostro and Radinsky emphasize how conceptual tools from different contexts afford varying degrees of agency and engagement with mathematics. From high school M4SJ, Calvin used the idea of mathematics as "realto-his-life" to narrate his identity as a science learner who can use math to explore phenomena of interest to him. In the problem-based, reformed mathematics course, connections to real life were present (e.g., the physics of a Ferris wheel), but they were made for students by instructors and curricular materials. Finally, in more traditional contexts, Calvin's agency was reduced to simply finding strategies to get through.

The authors also use the interview analysis to make an additional theoretical point. They highlight the importance of Calvin as the narrator of his own identity. Calvin did not take up the intended social justice themes of M4SJ, but rather appropriated for himself the idea of using math to look at the scientific world. Calvin's case makes salient the point that identity construction is not something that instructors or researchers can do for youth (Guitierrez, 2016).

Taken as a set, these papers present a theory of identity construction as a complex dynamic process involving interactions between actors and systems at different levels. They invite practitioners to use this theoretical understanding to design classroom activities and supporting patterns of talk that both disrupt harmful, dominant social narratives and make space for students to construct new ways of identifying within and beyond the disciplines.

\section{ACKNOWLEDGMENTS}

I would like to thank Jessica Watkins for bringing these papers to my attention.

\section{REFERENCES}

Boaler, J. (2008). Promoting relational equity and high mathematics achievement through an innovative mixed-ability approach. British Educational Research Journal, 34(2), 167-194

Gutierrez, K. D. (2016). 2011 presidential address: Designing resilient ecologies: Social design experiments and a new social imagination. Educational Researcher, 45(3), 187-196.

Gutstein, E. (2016). Reading and writing the world with mathematics: Toward a pedagogy for social justice. New York: Routledge. 